\title{
Search launched for lowest 'addictive' nicotine level
}

Washington. Last week's conclusion by an advisory panel of the US Food and Drug Administration (FDA) that nicotine is addictive has shifted the scientific focus of debate over the regulation of tobacco to the question of what dose sustains the addiction.

The conclusions of the FDA's drug abuse advisory committee may seem a statement of the obvious, although they are still disputed by scientists for the Tobacco Institute, which represents the views of the tobacco industry, who argue that nicotine does not intoxicate - and that intoxication is a defining symptom of addiction.

The FDA panel rejected that line of reasoning. At a meeting in Washington, DC, it agreed that nicotine's addictiveness is "substantially due to the pharmacological effects of nicotine on the human body". But it was unable to agree on the level of nicotine that is addictive.

The findings are critical to the FDA's current attempts, led by its commissioner, David Kessler, to assume jurisdiction over all tobacco products.

One of the main requirements for seeking such authority under existing legislation is that the substance changes the structure and function of the body; hence the FDA's focus on nicotine, even though other constituents of tobacco are more harmful.

But as the law now stands, if the agency were to assume jurisdiction it would have to ban tobacco products until the industry could prove their safety and efficacy. Such action would provoke a fierce political and social outcry. Legislation is currently before Congress that would allow the FDA to give a more moderate response - for example, to require new labels, spelling out the chemical content and addictive nature of cigarettes.

The phrasing on such labels may, in turn, require the FDA to decide whether -- and if so, at what level - there is any minimum dose leading to addiction. In the longer term, more drastic action is likely to follow. One congressional source anticipates that "within the next year or two Kessler will ban cigarettes with more than a particular level of nicotine and tar".

Such a ban would not cover all cigarettes containing addictive levels of nicotine. But it could lead to congressional approval of a variation of a strategy proposed by Neal Benowitz, chief of clinical pharmacology and experimental therapeutics at the University of California, San Francisco, and Jack Henningfield, chief of the clinical pharmacology branch of the National Institute of Drug Abuse (NIDA).

At last week's meeting, Benowitz and Henningfield suggested that the nicotine content of cigarettes should be reduced over 10 to 15 years to a level that does not maintain addiction. They argue that approach would both minimize the burden imposed by the 45 million Americans currently addicted to nicotine and reduce the number of new smokers.

But if this approach is adopted, it will require a consensus on the maximum level

\section{IMAGE UNAVAILABLE FOR COPYRIGHT REASONS}

Details of 'addiction' levels may soon be required on cigarette packaging.

of nicotine accepted to be non-addictive Benowitz and Henningfield suggest $5 \mathrm{mg}$ a day, on the basis of an analysis by Saul Schiffman, a psychologist at the University of Pittsburgh, of the roughly 10 per cent of smokers who are not addicted - those who can smoke one or two cigarettes every few days and stop without withdrawal symptoms.

A randomized double-blind trial of nicotine patches by David Sachs, director of the Palo Alto Center for Pulmonary Disease Prevention in California, suggests that the $5 \mathrm{mg}$ figure may be right.

Sachs, Benowitz and Henningfield all accept that more research is needed. Their studies are based on existing smokers, and their data may therefore not accurately reflect the dose needed to create an addiction.

Partly as a result of the FDA's recent action the National Cancer Institute (NCI) and the NIDA are likely to put out joint requests for research aimed at establishing the minimum dose of nicotine that is addictive, according to Thomas Glynn, associate director for cancer control science at the NCI.

Benowitz and Henningfield are themselves each seeking a physiological signal, such as a brain-wave pattern, that may indicate susceptibility to nicotine addiction. If such an indicator is found, pure nicotine could be administered to volunteers through a patch, and stopping long before an addiction develops. This would provide a measure of an average level of sensitivity to nicotine, from which regulators could establish a non-addictive dose for each cigarette.

Helen Gavaghan

\section{Pay-by-results leads to funding shift in Australian universities}

Sydney. A new performance-based system of allocating research funds to Australian universities, whose results were announced last week, has shifted funds away from the established institutions to a number of newly created universities.

As the new system rewards links with industry, it has also shifted millions of dollars away from institutions in relatively unindustrialized parts of the country, such as the University of Adelaide (in South Australia) and the University of Western Australia, towards those in the more heavily industrialized east coast.

The biggest loser, Adelaide University, will see its annual grant cut by A $\$ 3.8$ million (US\$2.8 million) by 1996. In anticipation of the cut, it has already decided to shed 90 staff, including 15 researchers, through voluntary redundancies.

The new funding system involves about 6 per cent (A\$248 million), of the general government grants provided to all Australian universities. The federal government has decided to allocate this sum as a "research quantum", allocated according to a 'composite index' that takes into account a range of 'input' and 'output' factors.

Inputs include the institution's success in winning research grants from funding bodies and from industry. Outputs include the number of publications and postgraduate completions.

One effect of this process has been to give more money to newer universities, many of which have been successful in attracting industry funding for research.

The University of Western Sydney, for example, founded in 1989, will see its share of the research quantum increase from a meagre $A \$ 300,000$ to around $A \$ 1.4$ million a year by 1996 . The Queensland University of Technology (formerly the Queensland Institute of Technology), will see its share of the research quantum rise from A\$1.3 million to A\$2.7 million a year in 1996 .

Professor Brian Wilson, vice-chancellor of the University of Queensland, which will receive an additional $\mathrm{A} \$ 2.7$ million a year by 1996 , claims that the university's success is based on its record in attracting both industry funds and government research grants in agriculture and mining.

In contrast, Mary O'Kane, deputy vicechancellor of research at the University of Adelaide, says that the university had suffered in the fight for industry funds because most Australian companies are based on the east coast. She said that the eventual cut of A $\$ 3.8$ million a year in the university's operating budget will be difficult to absorb, and will force it to look elsewhere for funds, particularly to Asia.

Mark Lawson 